\title{
The surface climatology of the eastern Mediterranean region obtained in a three-member ensemble climate change simulation experiment
}

\author{
S. O. Krichak, P. Alpert, K. Bassat, and P. Kunin \\ Department of Geophysics and Planetary Sciences, Raymond and Beverly Sackler Faculty of Exact Sciences, Tel Aviv \\ University, Tel Aviv, Israel
}

Received: 27 February 2007 - Revised: 29 May 2007 - Accepted: 2 July 2007 - Published: 6 July 2007

\begin{abstract}
Two configurations of RegCM3 regional climate model (RCM) have been used to downscale results of two atmosphere-ocean global climate model (AOGCM) simulations of the current (1961-1990) and future climates (20712100) over the eastern Mediterranean (EM) region. The RCM domain covering the EM region from northern Africa to central part of Asia Minor with grid spacing of $50 \mathrm{~km}$ was used. Three sets of RCM simulations were completed. Results of the RCM experiment support earlier projections of a temperature (annual precipitation) increase (decrease) to the end of 21st century over the EM. The roles of several major factors in controlling uncertainty of the climate change estimates are evaluated. The main uncertainty factors appear to be associated with possible inadequacies in RCM description of the EM-climate-controlling developments over remotely located areas as well as those in the simulations of the global climate and its trends by the AOGCMs.
\end{abstract}

\section{Introduction}

The Eastern Mediterranean region (hereafter EM) is characterized by sharp gradients of main climate parameters. The EM climate peculiarity is a joint consequence of the air-sea interactions, effects of regional topography and predominant wind directions causing air to dry-off during its way along the upwind slopes of the coastal zone. Significant for the EM climate is also the contribution of the large-scale climate effects associated with the inter-annual displacements of the Hadley cell and the trends of the Asian-African monsoon (Bedi et al., 1976). An impressive manifestation of the dependency is the well-known uneven character of annual distribution of precipitation over the southeastern EM, with practically all the precipitation falling out during the cool

Correspondence to: S. O. Krichak

(shimon@cyclone.tau.ac.il) season. A positive correlation of the EM precipitation with the indices of the east Atlantic - western Russia anomaly pattern (Krichak and Alpert, 2005) demonstrates the role of the weather processes over Europe in the EM climate. Intense EM precipitation events are usually associated with a southward propagation of the polar front jet and its interaction with the upper-troposphere subtropical jet stream. Such synoptic situations are often characterized by formation of potential vorticity (PV) streamer systems, penetration of Arctic air masses and intensification of the tropical-extratropical interactions over the region (Alpert et al., 2006; Krichak et al., 2007). Significance of the long-distance dependencies for understanding the EM climate and especially the EM precipitation regimes appears evident.

The peculiarity of the EM climate is also important for its hydrodynamic simulation. Relatively low-resolution (150$300 \mathrm{~km}$ ) of contemporary atmosphere-ocean global climate models (AOGCM) precludes accurate representation of the small-scale effects. A limited number of efforts on running regional climate models (RCM) driven from the lateral boundaries by the AOGCM (or reanalysis) data to downscale them over the EM region has been undertaken (Alpert et al., 2007 ; Evans et al., 2004; Giorgi et al., 2004a; Krichak and Alpert, 2004; Krichak et al., 2005; Pal et al., 2007). Although the simulations describe the main features of the EM climate, a number of problems remain unsolved. Among those the ability of the contemporary systems to reproduce frequency and intensity of occurrence of extreme precipitation, temperature and wind events remains insufficient. A positive bias in representation of summer air temperatures over arid areas has been reported (Krichak at al., 2005; Pal et al., 2007). The RCM simulations are affected by an insufficient accuracy of

\footnotetext{
${ }^{1}$ Alpert, P., Krichak, S. O., Osetinsky, I., Dayan, M., Haim, D., and Shafir, H.: Climatic trends to extremes employing regional modeling and statistical interpretation over the E. Mediterranean, Global Planet. Change, submitted, 2007.
} 


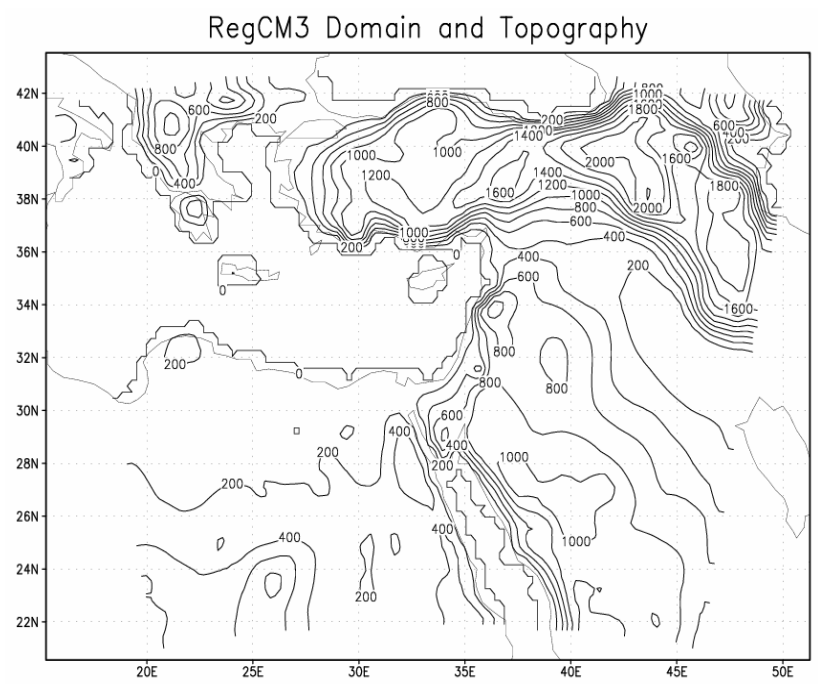

Fig. 1. Model domain and topography Units are $m$ and the contour interval is $100 \mathrm{~m}$.

description of different controlling the EM climate factors leading to an uncertainty in the modeling results.

Application of the RCM approach is also an accepted strategy for determination of the regional effects of the global climate change (e.g. Christensen and Christensen, 2003; Giorgi et al., 2004b). Limitations in accuracy of an RCM simulation of the current climate over a region seem to be also leading to uncertainty in the estimates of the future climate change with the same model. In addition to the uncertainties derived from model formulations also those derived from natural climate variability and future atmospheric emissions are usually addressed (Christensen and Christensen, 2003). Additional efforts for determination of the main active factors and their relative contribution in the RCM simulations are required.

A multi-model approach has been adopted in a European climate modeling effort under the EU PRUDENCE Project (Christensen and Christensen, 2003; Giorgi et al., 2004a, b; Deque et al., 2005). In this project the EM area was covered however by only one of the RCM experiments (Giorgi et al., 2004a, b). A similar strategy for performing hydrodynamic simulation of the EM climate has been applied in the current study.

\section{Experimental design}

The primary aim of the effort was to determine directions for future optimizations of the RCM system at Tel Aviv University (TAU). The evaluations are focused on quantification of uncertainties in the modeling results due to (a) the RegCM3 internal variability and (b) quality of the driving data in the climate projections. Additional mechanisms leading to uncertainties in the results are those associated with (mainly computationally induced) oscillations in the AOGCM data as well as long-term natural variability of the real climate. It is assumed here, that the oscillations are filtered out by the time-averaging of the 30-year RCM data.

The RegCM3 model (Pal et al., 2007) of the International Center for Theoretical Physics (ICTP), Trieste, Italy has been adopted. A three-member ensemble RCM experiment has been realized. The EM climate during the current (CT, 19611990) and future (2071-2100, A2 and B2 IPCC 2000) 30year periods was simulated. To account for effects of uncertainty due to different formulations of driving data, the boundary data used were from two climate simulation experiments, with the UK Met. Office Hadley Center HadCM3, additionally downscaled with a global atmosphere-only model (HadAM3P), forced by surface boundary conditions (seasurface temperature and sea-ice fraction) from HadCM3 (Johns at al., 2003) and observations and NASA Finite Volume FV-GCM global atmosphere-ocean models (Atlas et al., 2005).

The A2 and B2 (IPCC 2000) scenarios were adopted in the experiment. According to the IPCC A2 scenario global $\mathrm{CO}_{2}$ emissions will increase by more than fourfold over their 1990 level to $2100\left(\mathrm{CO}_{2}\right.$ concentration of about $850 \mathrm{ppm}$ by 2100$)$ A less intense $\mathrm{CO}_{2}$ emission is projected to the 21 st century by the $\mathrm{B} 2$ scenario $\mathrm{CO}_{2}$ concentration of about $600 \mathrm{ppm}$ by 2100. Within the full range of the IPCC emission scenarios, the A2 lies towards the upper end, while the B2 scenario lies towards the lower end. The two scenarios encompass about half of the IPCC emission scenario range. Only one future climate (A2 scenario) simulation experiment was performed with the FV-GCM. The A2 and B2 (IPCC 2000) scenarios were adopted in the HadCM3-HadAM3P experiments. Finally, it must also be noted that new observation data (Raupach et al., 2007) demonstrate a more intense than expected by the $\mathrm{B} 2$ scenario $\mathrm{CO}_{2}$ emission during the first years of 21 st century.

The same model domain covering a significant part of the EM from northern Africa to central Asia Minor with the gridspacing of $50 \mathrm{~km}$ (Fig. 1) was used in all the simulation runs. To account for uncertainties due to different active factors three RCM runs performed were characterized by different model setups. Two of the runs (PRCS1 and PRCS2) used HadAM3-based driving data and one of them (FVGCM) the FV-GCM ones. Prameterization of chemistry/aerosol effects was not activated. Additional details of the RCM and AOGCM simulations are given in Table 1.

In the following, unless otherwise specified, we refer to the term "change" as the difference between the selected climate statistics in the scenario (2071-2100) and reference (1961-1990) simulations. Both results of simulation of the current EM climate and its future change due to the anthropogenic emission of greenhouse gases (GHG) are discussed here. In accordance with this, the simulated current climate patterns of several meteorological parameters and those of the changes projected to the end of 21 st century are discussed below in comparison to the observation data available. 
Table 1. Characteristics of the simulation experiments.

\begin{tabular}{lllll}
\hline $\begin{array}{l}\text { RCM } \\
\text { Experiment }\end{array}$ & $\begin{array}{l}\text { GCM } \\
\text { used }\end{array}$ & $\begin{array}{l}\text { GCM } \\
\text { resolution }\end{array}$ & $\begin{array}{l}\text { RegCM3 } \\
\text { resolution }\end{array}$ & $\begin{array}{l}\text { Convective } \\
\text { parameterization }\end{array}$ \\
\hline PRCIS1 & $\begin{array}{l}\text { HadCM3- } \\
\text { HadAM3P }\end{array}$ & $\begin{array}{l}\left(2.5^{\circ} \times 3.75^{\circ}\right) / \mathrm{L} 19 \\
\left(1.875^{\circ} \times 1.875^{\circ}\right) / \mathrm{L} 19\end{array}$ & $50 \mathrm{~km} / 14 \mathrm{~L}$ & Grell/FC \\
PRCIS2 & HadCM3- & $\begin{array}{l}\left(2.5^{\circ} \times 3.75^{\circ}\right) / \mathrm{L} 19 \\
\left(1.875^{\circ} \times 1.875^{\circ}\right) / \mathrm{L} 19\end{array}$ & $50 \mathrm{~km} / 18 \mathrm{~L}$ & Grell/FC \\
& HadAM3P & $\left(1^{\circ} \times 1.25^{\circ}\right) / \mathrm{L} 18$. & $50 \mathrm{~km} / 18 \mathrm{~L}$ & Emanuel \\
\hline
\end{tabular}

\section{Results}

\subsection{Simulation of current climate}

Evaluation of the RCM-produced long-term (30 year) mean patterns of summer and winter distributions of near-surface air temperatures, winds, net absorbed short-wave radiation and annual precipitation over the northern (southern Turkey), central (Lebanon, Syria and Israel) and southern (Egypt, Palestinian Autonomy area and Israel) parts of the EM is performed below in comparison to the 30-year mean (19611990) data from the Climate Research Unit (CRU) of the University of East Anglia, UK (Mitchell et al., 2004). The CRU data are available with $0.5^{\circ}$ spacing based on the observations from land stations only. The fact additionally complicates evaluation of the RCM results over Sea areas. It must be noted here, that no validation of results of simulation of the surface wind and radiative fluxes over the region was performed earlier (Christensen and Christensen, 2003; Evans, 2004; Giorgi et al., 2004a, b).

\subsubsection{Air temperature}

The long-term mean winter (December-January-February, DJF) near-surface air temperatures simulated in the PRCS1, PRCS2 and FVGCM experiments are presented in Figs. 2ac, respectively. The corresponding CRU air temperatures are given in Fig. 2 d. A small negative $\left(\sim 1^{\circ} \mathrm{C}\right)$ bias characterizes the model-produced winter temperatures over the northern part of the region in the PRCS1 and PRCS2 results (Figs. 2a, b). The FVGCM results (Fig. 2c) are characterized by a positive $\left(\sim 3^{\circ} \mathrm{C}\right)$ bias however. An overestimation of the DJF temperatures is also found in the FVGCM results (Fig. 2c) over the central part of the EM, whereas the PRCS1 and PRCS2 data (Figs. 2a, b) quite accurately represent the real temperatures here. A good agreement between the modelproduced and observed DJF temperatures is found over the southern part of the region in all the three experiments.

Results of simulation of the summer (June-July-August, JJA) near-surface air temperatures and CRU data are presented in Figs. $3 \mathrm{a}-\mathrm{d}$, respectively. A positive $\left(\sim 2^{\circ} \mathrm{C}\right)$ bias characterizes the simulated JJA temperatures over the northern part of the EM region in the PRCS1 and PRCS2 data
(Figs. 3a, b). The FVGCM results (Fig. 3c) are characterized by a more significant $\left(\sim 3-5^{\circ} \mathrm{C}\right)$ positive bias. Also positive $\left(\sim 4^{\circ} \mathrm{C}\right)$ temperature bias is found in the FVGCMbased RCM results (Fig. 3c) over the central part of the EM, whereas results of the PRCS1 and PRCS2 (Figs. 3a, b) represent real data with only a small positive bias here. The warm area simulated south of Cyprus in PRCS1 experiment is not found in results of the other two experiments (Figs. 3b, c) and is not supported by the observations (Fig. 3d). The spot appears to be a model artifact, possibly indicating an insufficiency of the vertical resolution in the experiment. Over the southern part of the region the model overestimates the JJA temperatures by about $2^{\circ} \mathrm{C}$ in the PRCS1, PRCS2 experiments, but the temperatures produced in the FVGCM experiment are higher than those observed by about $4^{\circ} \mathrm{C}$. Further remark about the temperature biases is given in next subsection, in connection to the precipitation results.

\subsubsection{Annual precipitation}

Long-term mean annual precipitation CT patterns from the PRECS1, PRECS2 and FVGCM experiments as well as the corresponding CRU-based pattern are given in Figs. $4 \mathrm{a}-\mathrm{d}$, respectively. The four figures are quite similar in their major details. It must be noted however that the RCM experiments performed did not reproduce the sharp east-west gradient of the real precipitation distribution. Over the land areas the modelling results are characterized by a negative bias. Most successfully the CT EM annual precipitation is simulated in the FVGCM experiment (Fig. 4c). At the same time, the CT precipitation over the northern part of the EM is better reproduced by the PRCS2 experiment (Fig. 4b). Over the central EM results of the PRCS1 (Fig. 4a) experiment are closer to the real pattern than those of the PRCS2. Too high precipitation amounts are simulated in FVGCM experiment over a number of locations, including that over the mountainous area at the Lebanon-Surya border however. The higher amount of the FVGCM-based annual precipitation may be explained by the increase of the air-moisture content due to the positive temperature bias detected. The earlier noted biases in the summer and winter FVGCM-based temperatures could be caused by an excessive intensity of the warm airmass influx from the lateral boundaries. 
(a) PRCS1 temp DJF RegCM3

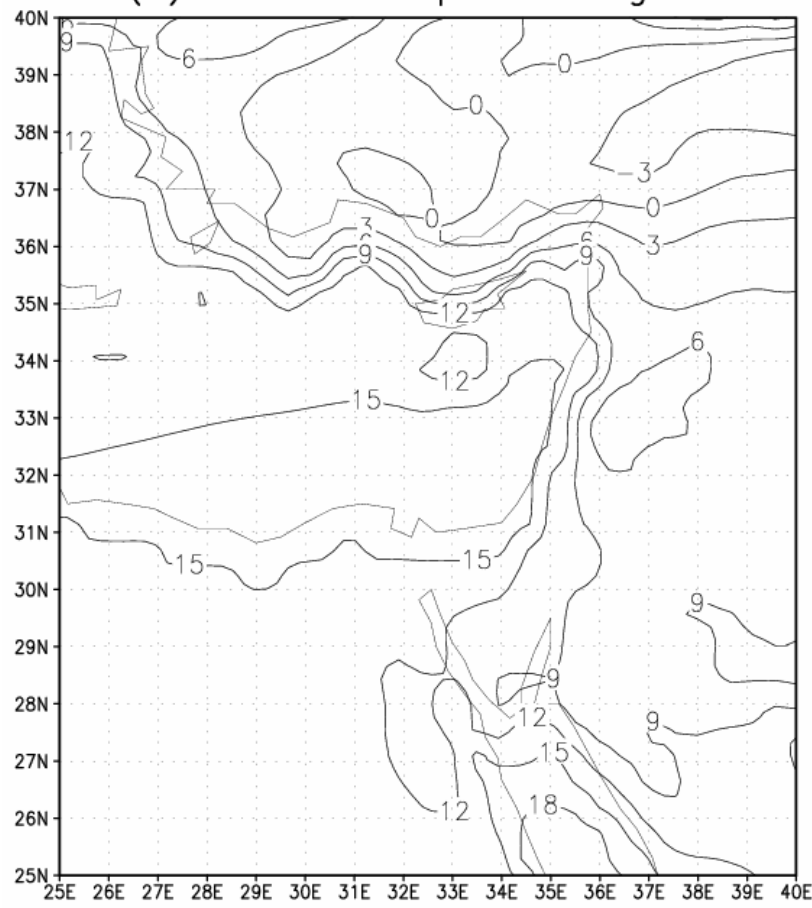

(c) FVGCM temp DJF RegCM3

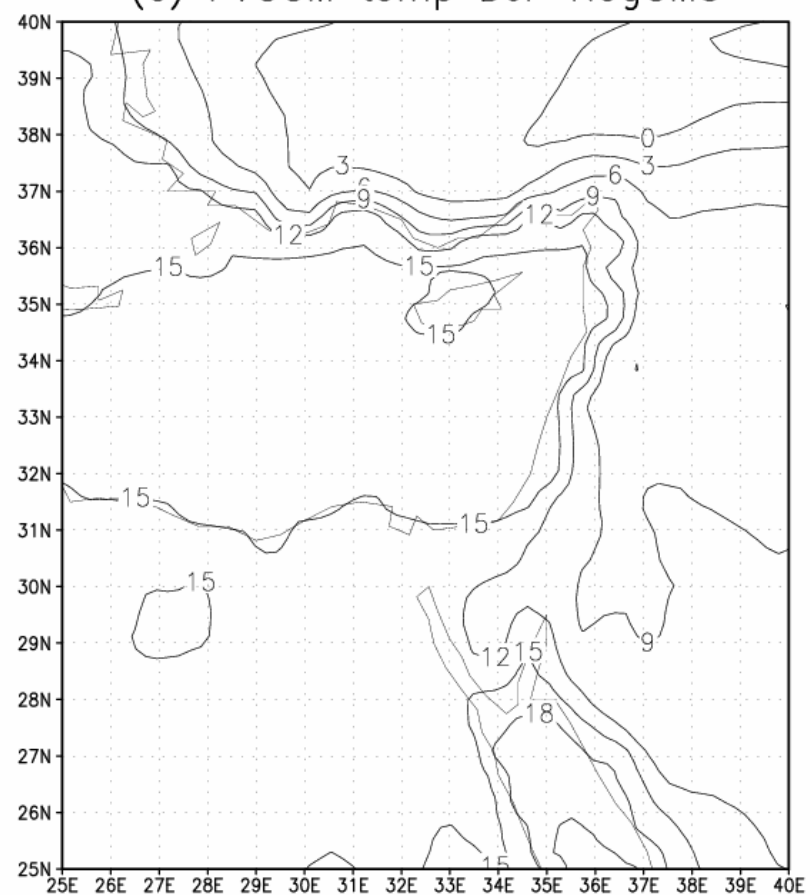

(b) PRCS2 temp DJF RegCM3

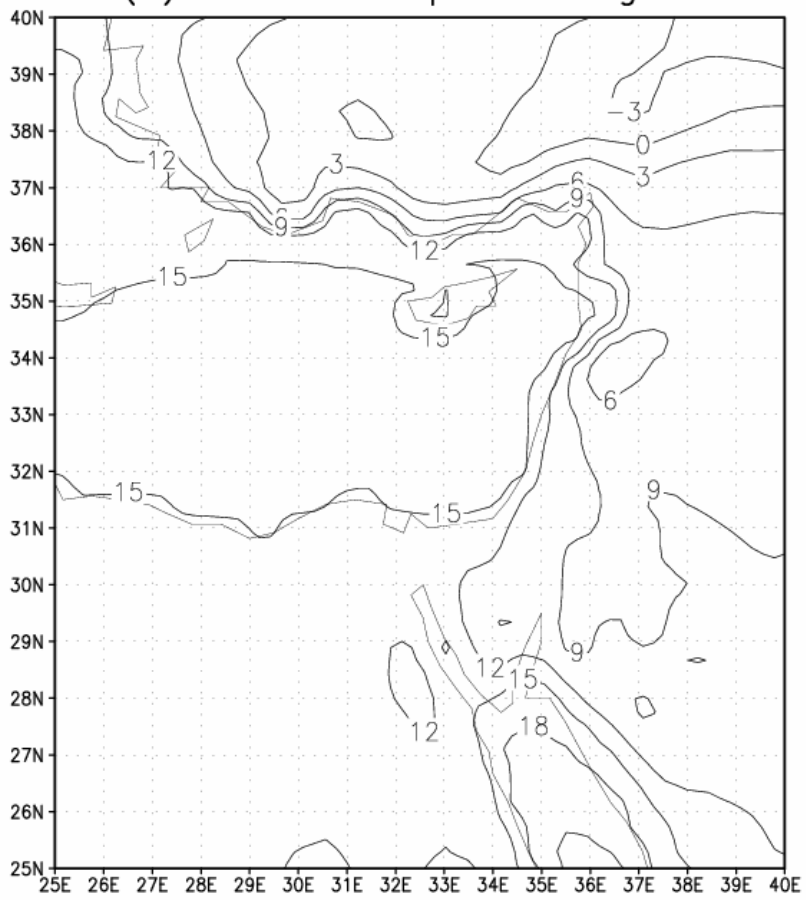

(d) CRU temp DJF

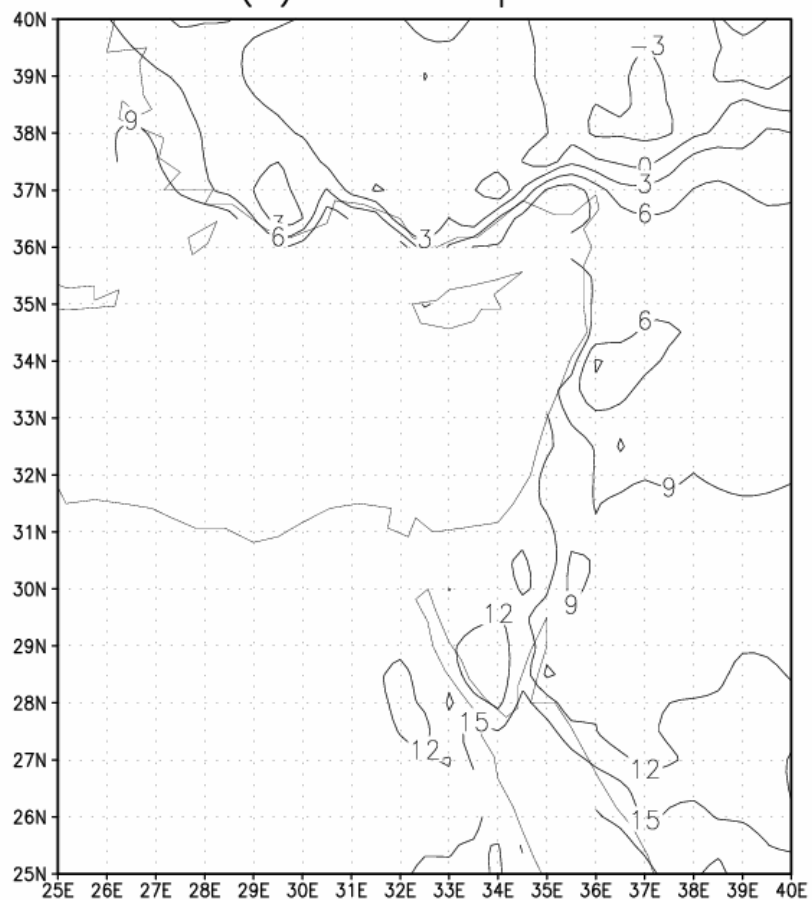

Fig. 2. December-January-February long-term mean near surface air temperature $\left({ }^{\circ} \mathrm{C}\right)$ produced in (a) PRCS1, (b) PRCS2, (c) FVGCM experiments and (d) CRU data. 
(a) PRCS1 temp JJA RegCM3

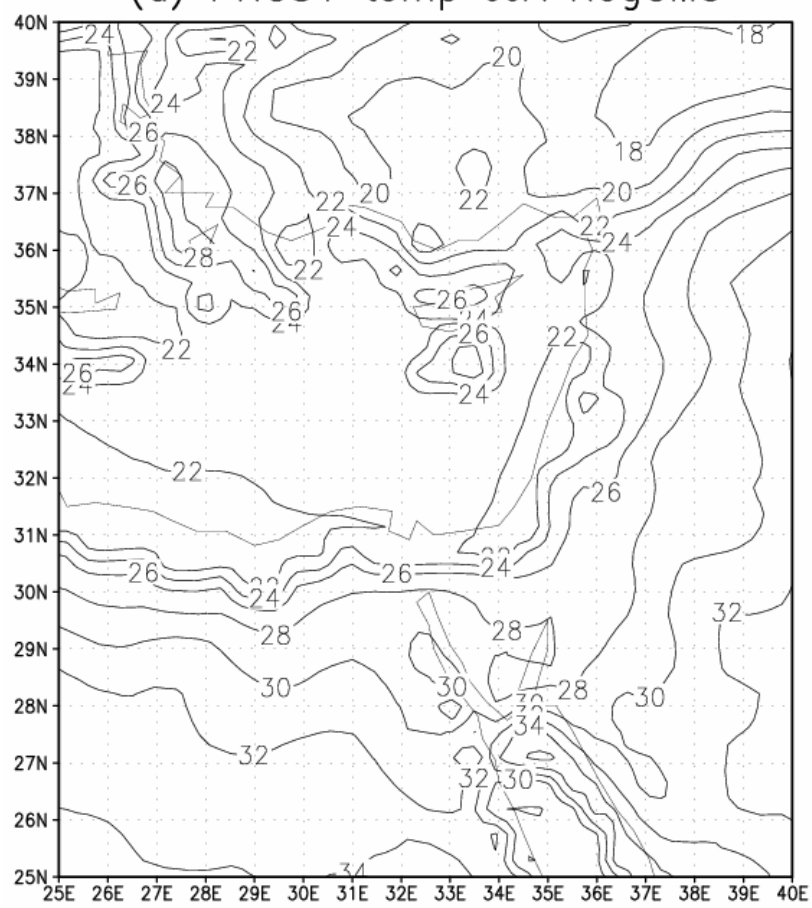

(c) FVGCM temp JJA RegCM3

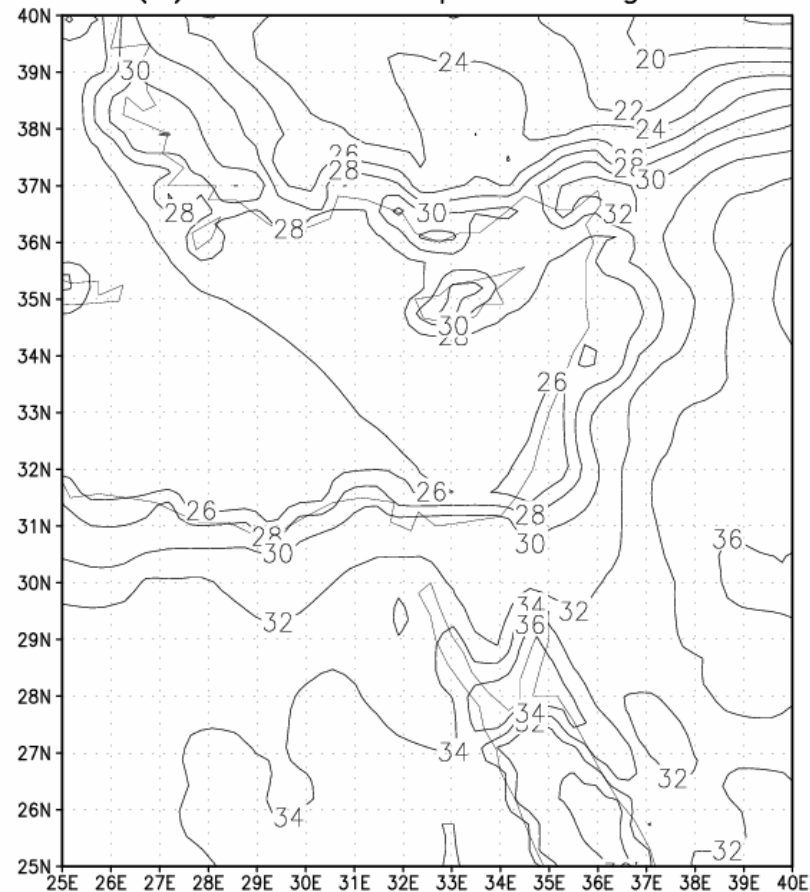

(b) PRCS2 temp JJA RegCM3

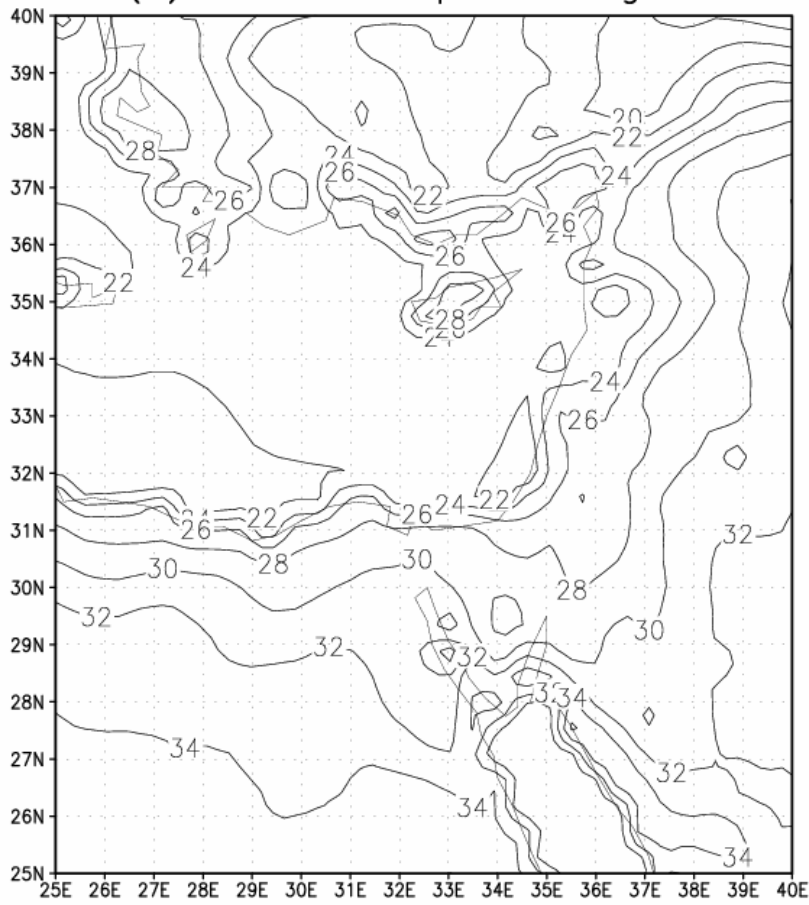

(d) CRU temp JJA

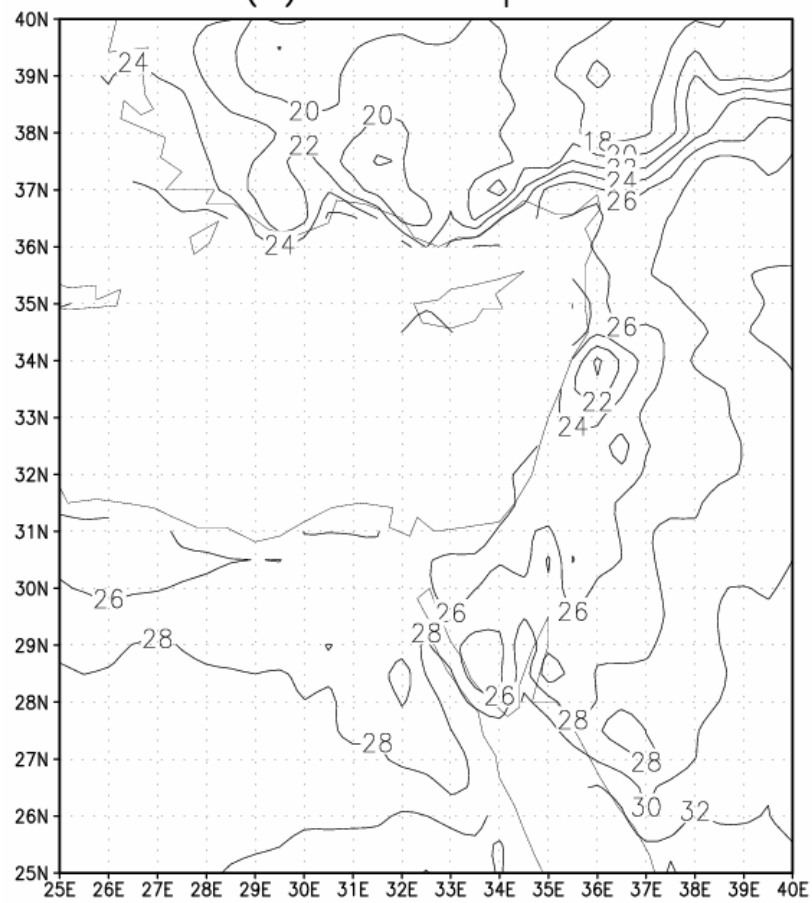

Fig. 3. Same as in Fig. 2 but for June-July-August season. 
(a) PRCS1 annual precip RegCM3

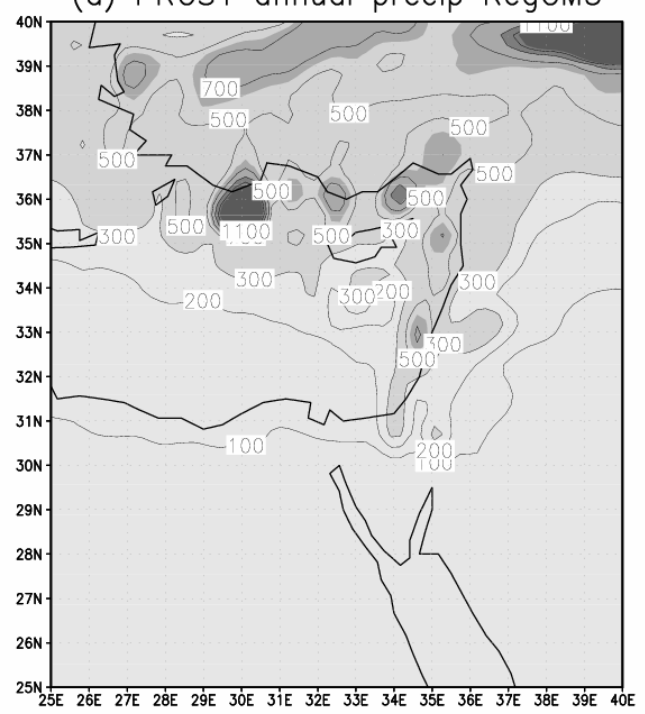

(c) FVGCM annual precip RegCM3

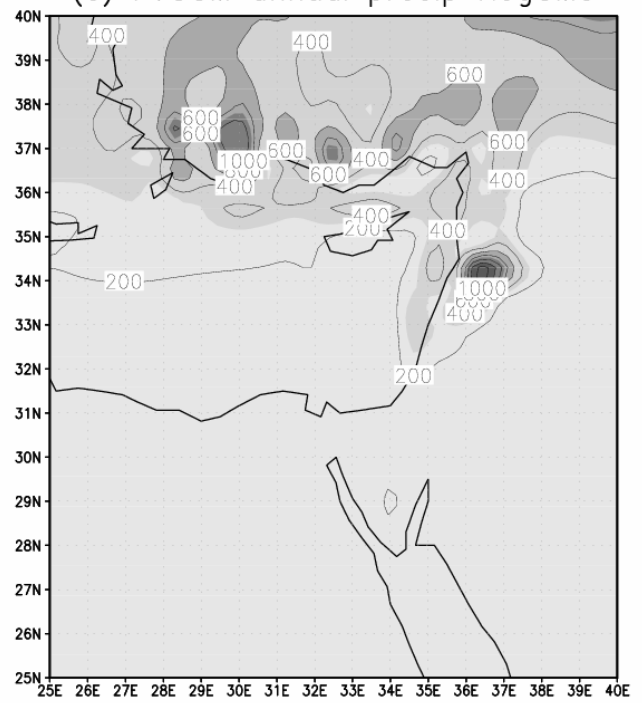

(b) PRCS2 annual precip RegCM3

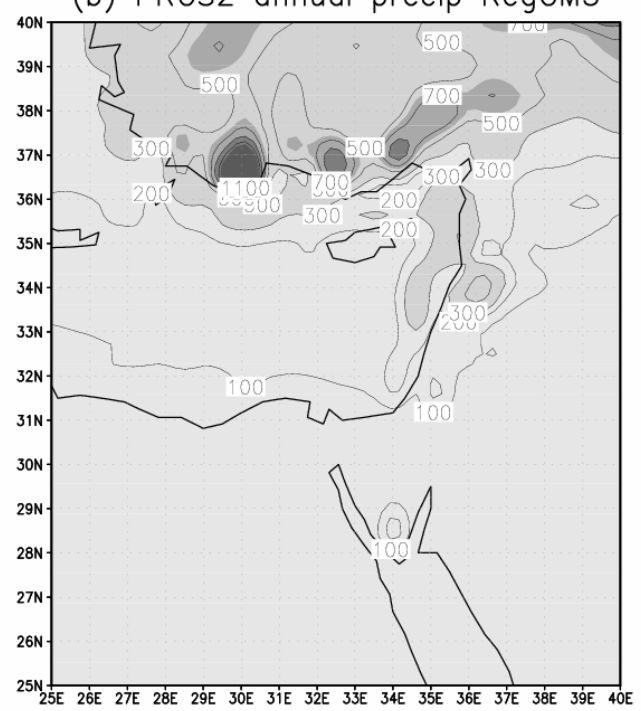

(d) CRU annual precip

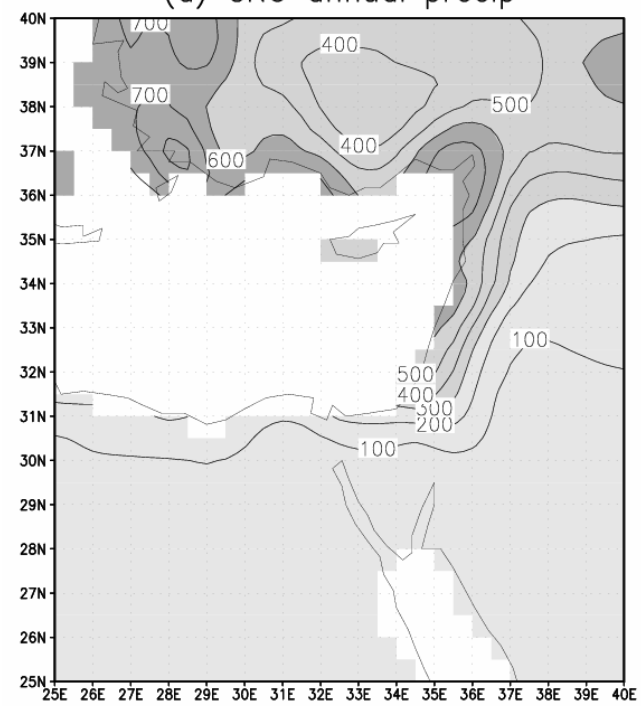

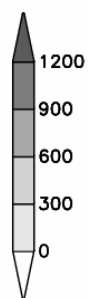

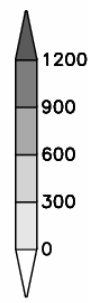

Fig. 4. Same as in Fig. 2 but for annual precipitation (mm).

\subsubsection{Wind}

The following discussions are limited by evaluation of results of the PRCS1 only. The model simulated winds are presented in Figs. 5a-d. The DJF and JJA winds are presented in Figs. 5a and c. The corresponding CRU data (only wind intensity data are available from the CRU archive) are given in Figs. 5b and d. Simulated DJF wind pattern (Fig. 5a) is characterized by mild west-north-westerly winds over the southern EM, westerly, south-westerly winds over central EM, southern and south-eastely winds over northern EM and relatively strong north-easterly winds $\left(\sim 4 \mathrm{~m} \mathrm{~s}^{-1}\right)$ over northeastern part of the Mediterranean Sea area. The most intense $\left(>4 \mathrm{~m} \mathrm{~s}^{-1}\right)$ are found over the north of Cyprus area of the

Sea. Due to the use of land only data by the CRU, the wind maximum may not be found in Fig. 5b. Over land regions however, intensities and location of the areas with simulated wind maxima over northern and southern EM are in good agreement with the observations. The EM JJA air flow patterns are similar to that of DJF in the southern and central parts of the area but significantly differ over the northern EM where northerly, north-easterly winds are found in the model simulated pattern (Fig. 5c). Positioning of the wind maxima areas over northern part of central EM and Red Sea area may be noted in the figure. Locations of the simulated areas with wind maxima are in reasonably good agreement with the CRU data (Fig. 5d). 
(a) PRCS1 wind DJF RegCM3

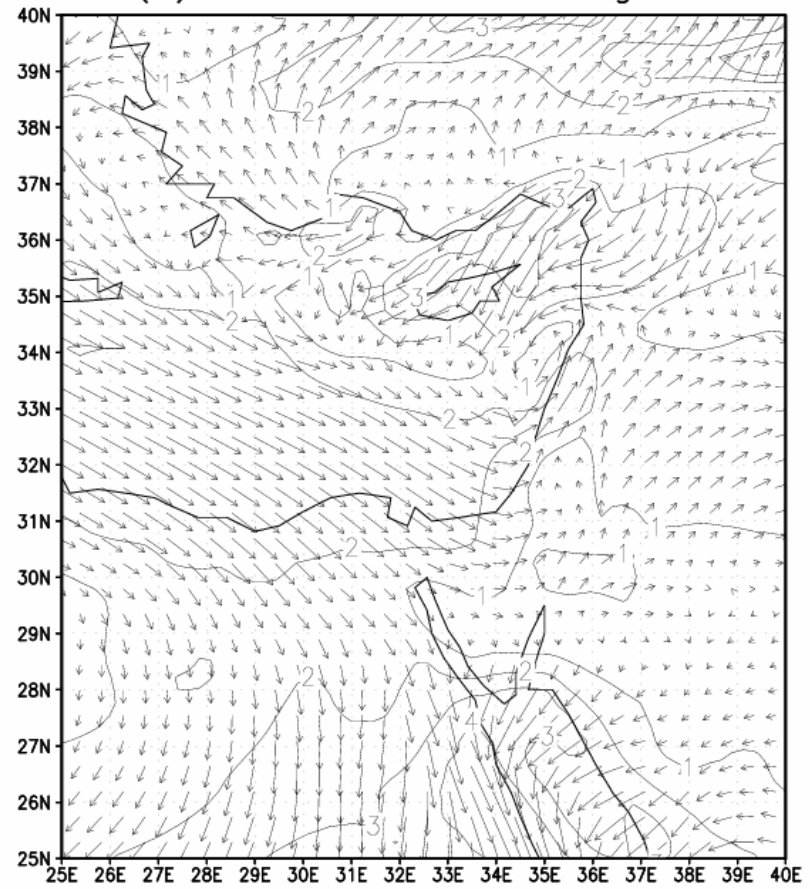

$\longrightarrow$ (b) CRU wind DJF
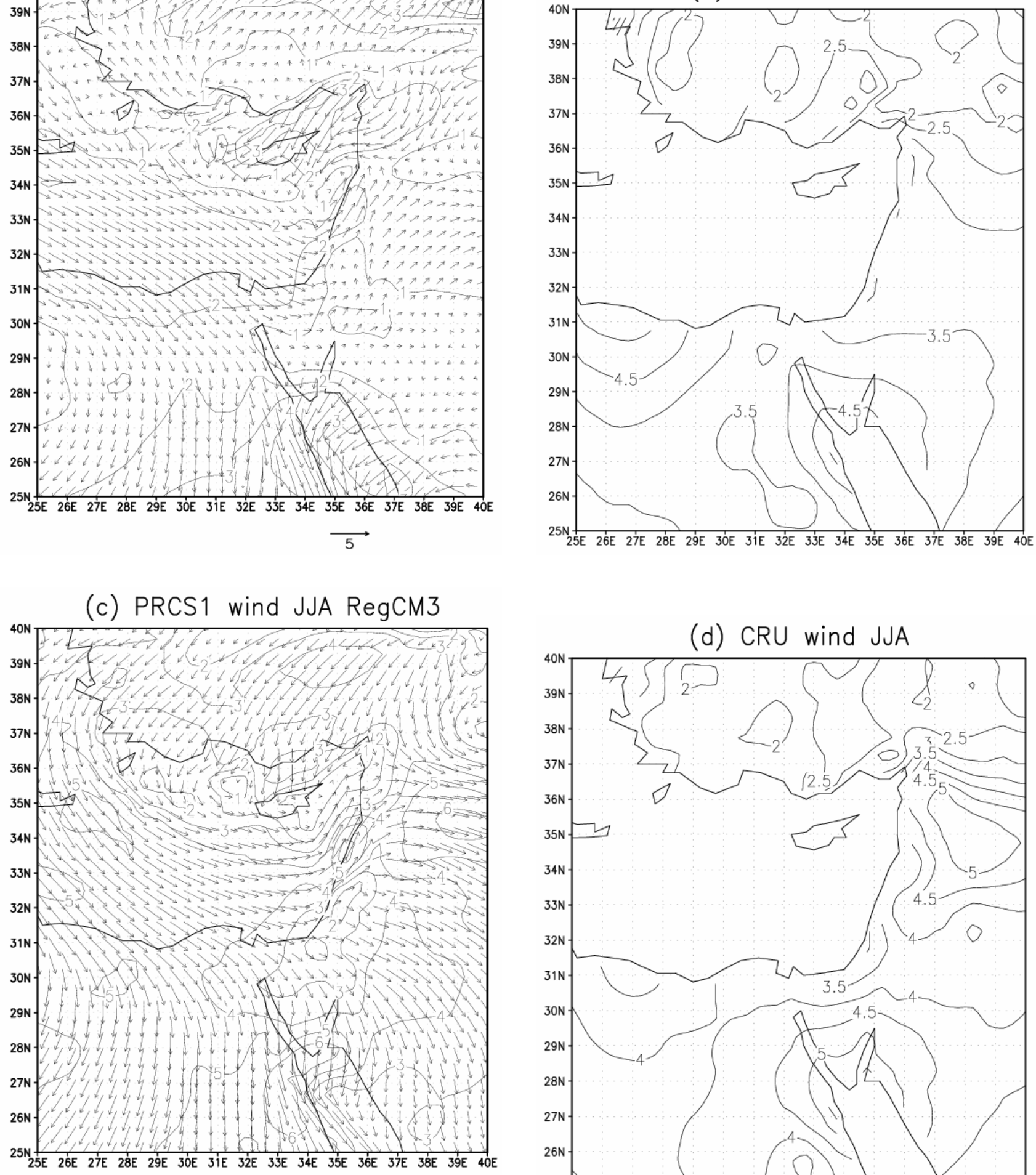

8 (d) CRU wind JJA

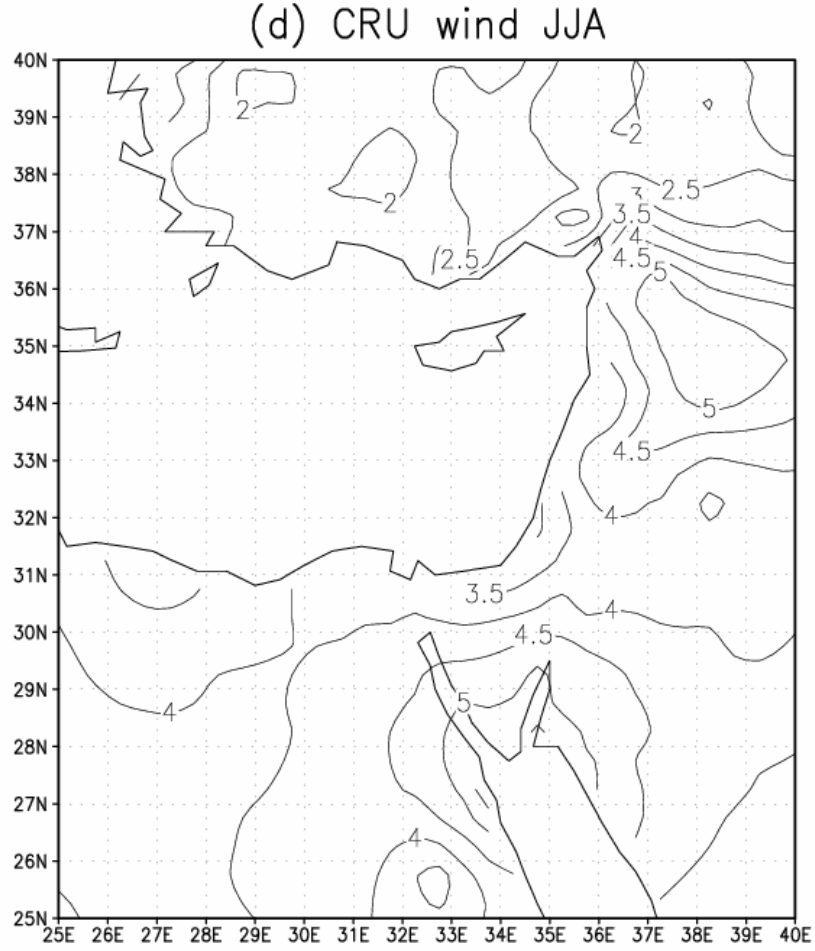

Fig. 5. Near surface winds directions and magnitudes (given by shadings and arrows' length) (a, c) simulated for DJF, JJA seasons, (b, d) DJF, JJA near-surface wind magnitudes - CRU data. 


\subsubsection{Radiative flux}

Radiative fluxes are an important climate component. The model simulated patterns with the net absorbed short-wave DJF and JJA radiation are presented in Figs. 6a and c, respectively. Corresponding verification data are given in Figs. 6b and d. Simulated DJF net absorbed SW pattern (Fig. 6a) is characterized by a large enough latitudinal gradient of the flux $\left(\sim 100 \mathrm{~W} \mathrm{~m}^{-2}\right)$. A different (east-west) orientation of the SW flux gradient characterizes the JJA simulated (Fig. 6c) and observed (Fig. 6d) patterns over the EM region. The model successfully reproduces the observed pattern over most of the area. A slight negative bias may be noted over the eastern boundary area. The bias may be resulting from an insufficient accuracy of the driving data.

\subsection{Future climate change}

Expected changes of a number of climate parameters due to the anthropogenic emission of greenhouse gases in the EM region have been discussed by Giorgi et al. (2004b) based on results of RCM simulations at the ICTP (using a differently configured RegCM model) driven by results of the same AOGCM - HadCM3 experiment (downscaled with a different AGCM - HadAM3H). Main results of our RCM experiment are in agreement with those of Giorgi et al. (2004b). In particular, both (Giorgi et al., 2004b and our (not presented) climate change experiments project a $20 \%$ decrease in amount of DJF precipitation and increase of DJF (up to $3^{\circ}$.) as well as JJA (up to $4-5^{\circ}$.) temperatures over the central EM. In the current study only results of simulation of the simulated changes in the surface wind and net absorbed solar radiation patterns are presented. The information is given in the form of patterns representing the mean future (20712100) and current (1961-1990) differences between the future (A2 scenario) and CT as well as A2 minus B2 climate conditions.

\subsubsection{Wind}

The model simulated A2-CT changes in 30-year mean DJF wind patterns are presented in Fig. 7a. The corresponding A2-B2 differences are given in Fig. 7b. The results demonstrate a large enough $\left(\sim 1 \mathrm{~m} \mathrm{~s}^{-1}\right)$ decrease in intensity of the south-westerly air-flow over the central EM region due to the climate change process both the case of A2 and B2 scenarios of the climate change. The wind intensity change is apparently among the factors partly responsible for the projected decrease in DJF precipitation. A similar DJF wind climate change effect is projected by the model experiment for the southern EM region. Over the north-eastern part of the Sea area the projected A2-scenario climate change is associated with a $0.5 \mathrm{~m} \mathrm{~s}^{-1}$ intensification of the northerly air-flow over the area of the Cyprus Island. The change may mean an increase in cyclogenetic activity over the climatologically sen- sitive area (Krichak et al., 2006) and that in intensity of extreme precipitation events in the area. Additional analyses and higher-resolution RCM simulations may be required to investigate the issue.

The corresponding JJA changes in the wind patterns are given in Figs. 7c, d. The climate change experiment consistently projects a $\sim 1 \mathrm{~m} \mathrm{~s}^{-1}$ weakening of the westerly airflows over the central and south-eastern parts of the EM region. The process may be representing the earlier mentioned significant air-temperature increase in the area due to the climate change process.

\subsubsection{Radiative flux}

The experiment's results for the net absorbed SW radiative flux are given in Figs. 8a-d. According to the pictures presented an increase in the solar radiation flux is expected (both in the case of A2 and B2 scenarios) over the northern part of the region. The increase is of about $25 \%$ (up to $20 \mathrm{~W} \mathrm{~m}^{-2}$ ) over the northern part of the area, whereas over the central EM it is much smaller $(\sim 5 \%)$. For the JJA period the $\mathrm{RCm}$ experiment consistently projects a quite insignificant increase in the radiative flux over the northern part of the region. Over the central EM no changes are projected. Over the southern part of the region a slight decrease in the flux intensity is expected.

\section{Effect of driving data}

HadAM3H based projections of the Sea Level Pressure (SLP) changes to the end of 21st century are presented in Figs. 9a-d. Namely, the A2-CT SLP changes are given in Figs. 9a,c for DJF and JJA respectively. Corresponding A2B2 differences are given in Figs. 9b, d. According to Fig. 9a, the DJF SLP change over S. Europe is expected to be characterized by a dipole structure with negative SLP anomaly over north-western Europe and positive SLP anomaly over and to the north of the EM. The dipole pattern resembles that of the negative phase of the East Atlantic/Western Russia (EA/WR) teleconnection pattern (Krichak et al., 2005). The climate change projection assumes an intensification of southerly airflow over the EM. Such atmospheric circulation anomaly is appropriate for drier than the current weather conditions over the region. An extending from the north-east positive SLP anomaly area is found over the Mediterranean area meaning positioning of an additional clockwise circulation change cell over the EM. The earlier discussed RCMprojected DJF wind changes (Fig. 7a) are in agreement with the pattern in Fig. 9a which means a large-scale origin of the RCM-simulated A2-CT DJF circulation change. 
(a) PRCS1 SW net DJF RegCM3

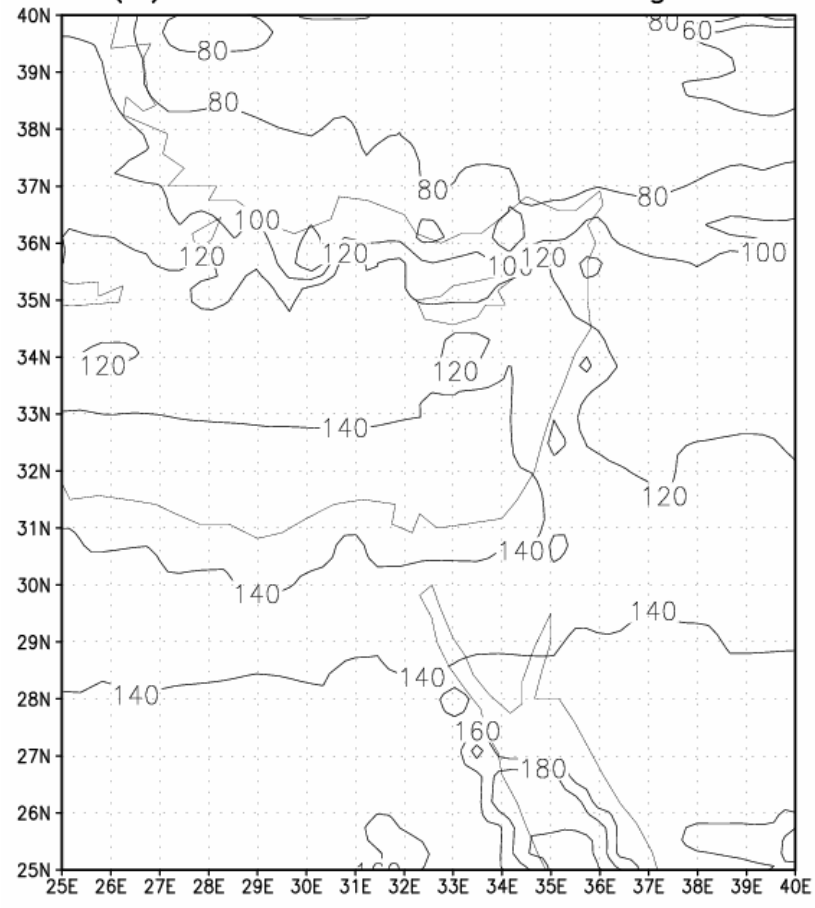

(c) PRCS1 SW net JJA RegCM3

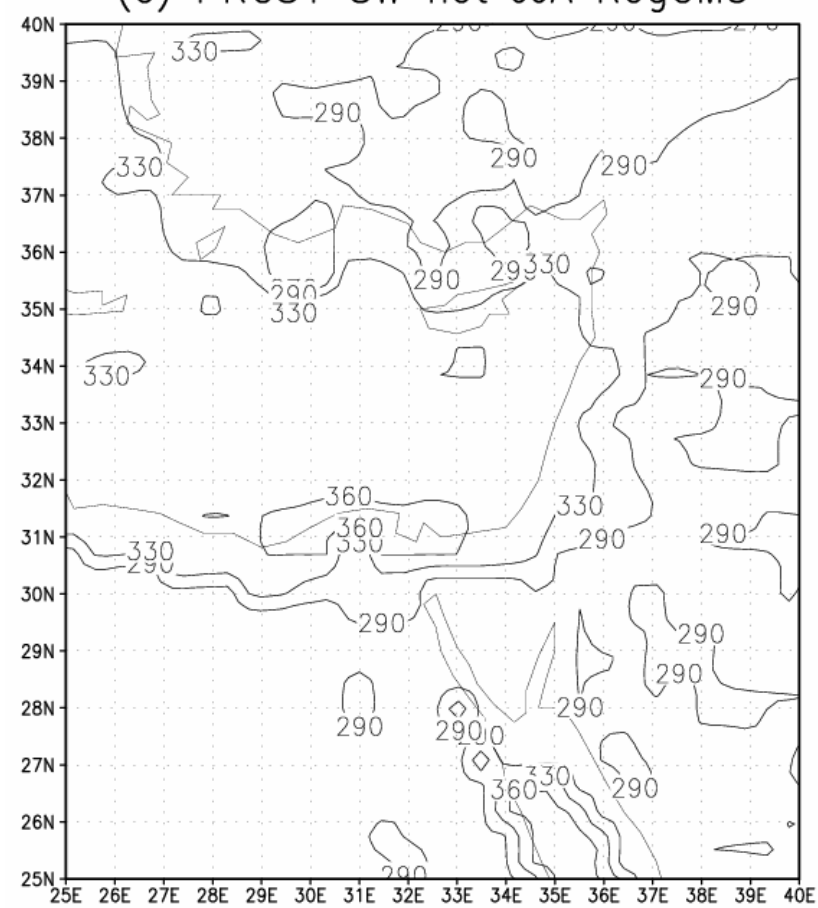

(b) CRU SW net DJF

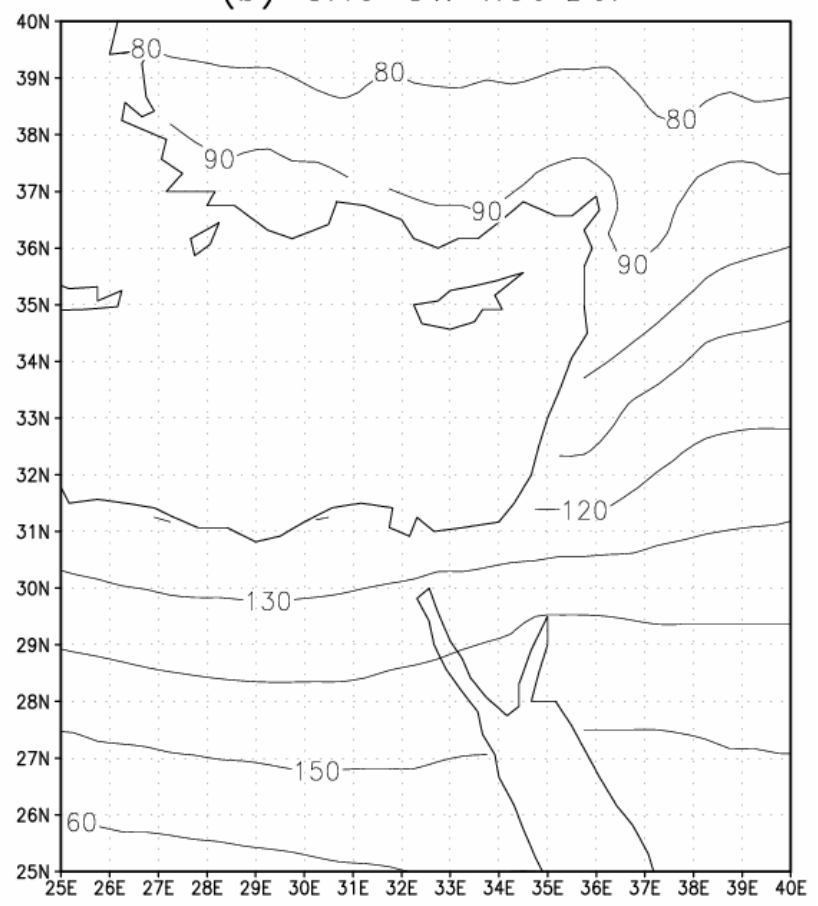

(d) CRU SW net JJA

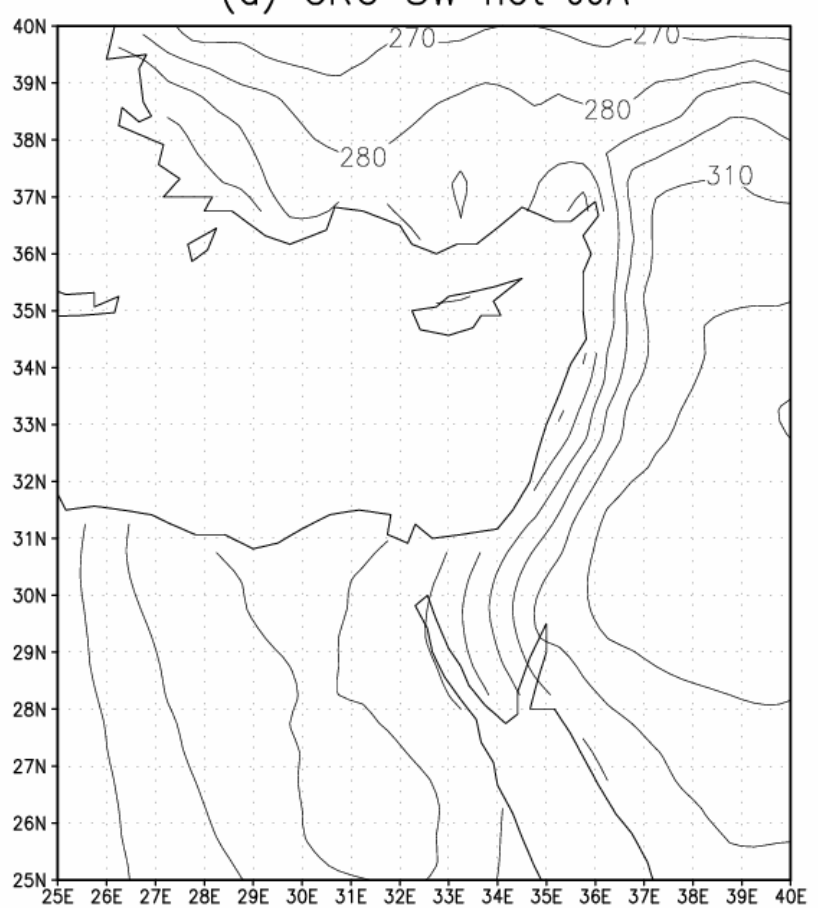

Fig. 6. Same as in Fig. 5 but for net absorbed short-wave radiation. 
(a) PRCS1 A2-CT wind DJF RegCM3

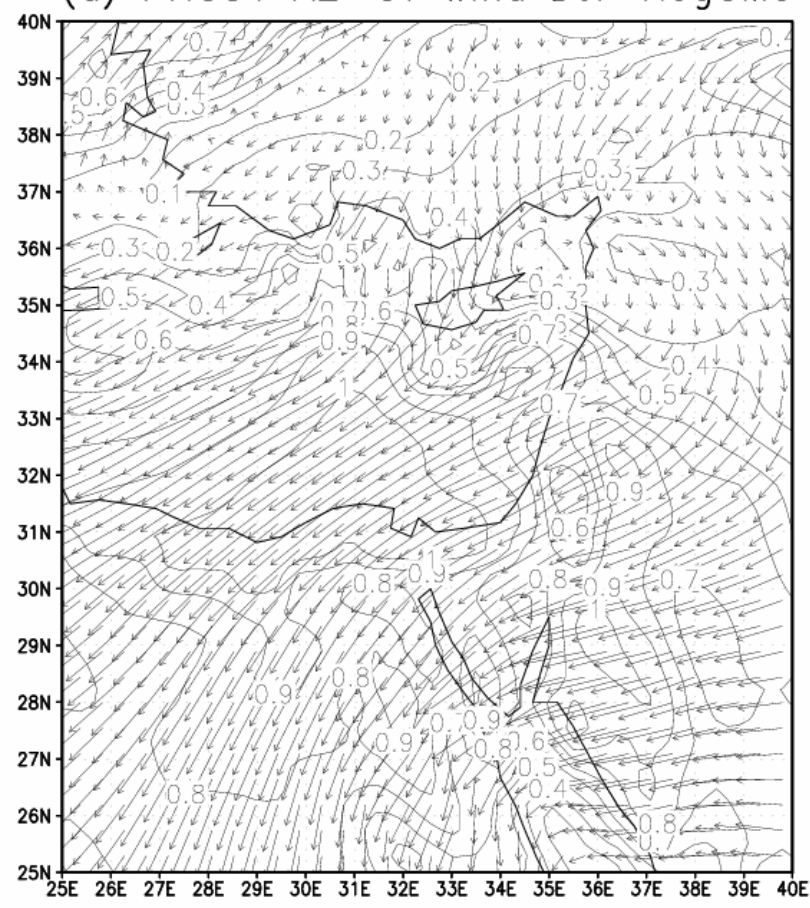

$\longrightarrow$

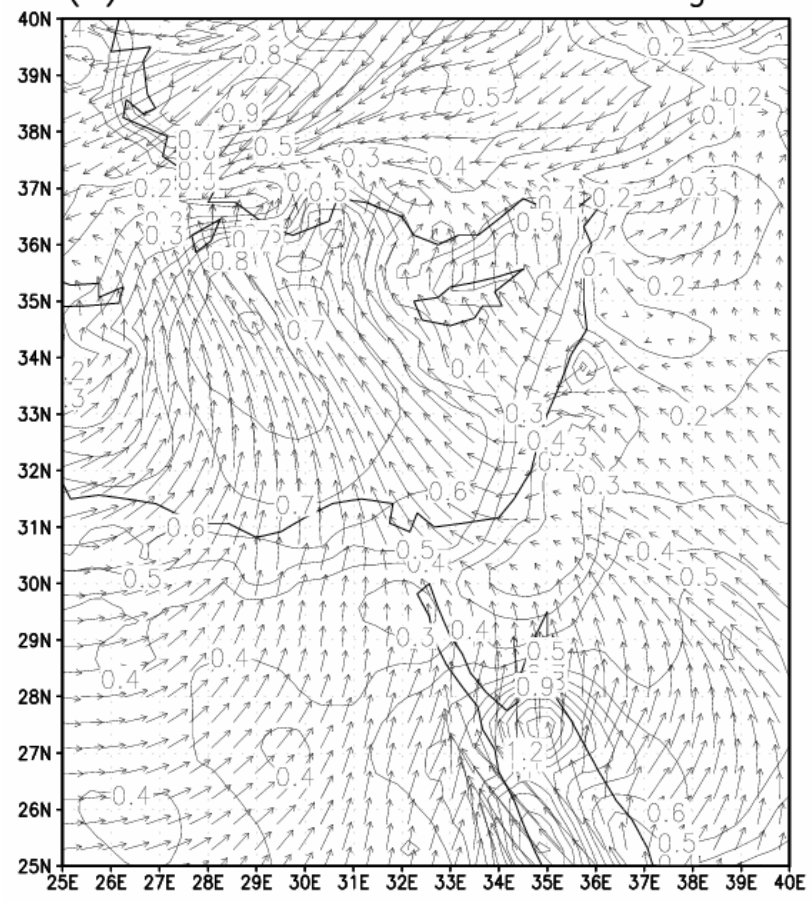

$\longrightarrow$ (b) PRCS1 A2-B2 wind DJF RegCM3

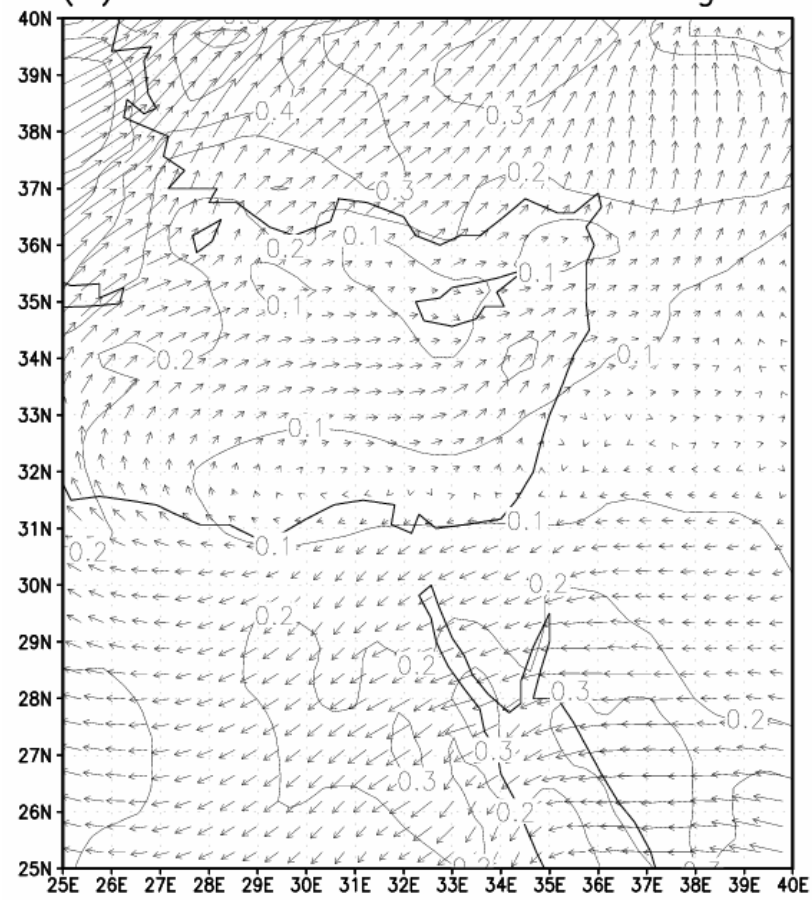

$\overrightarrow{0.7}$

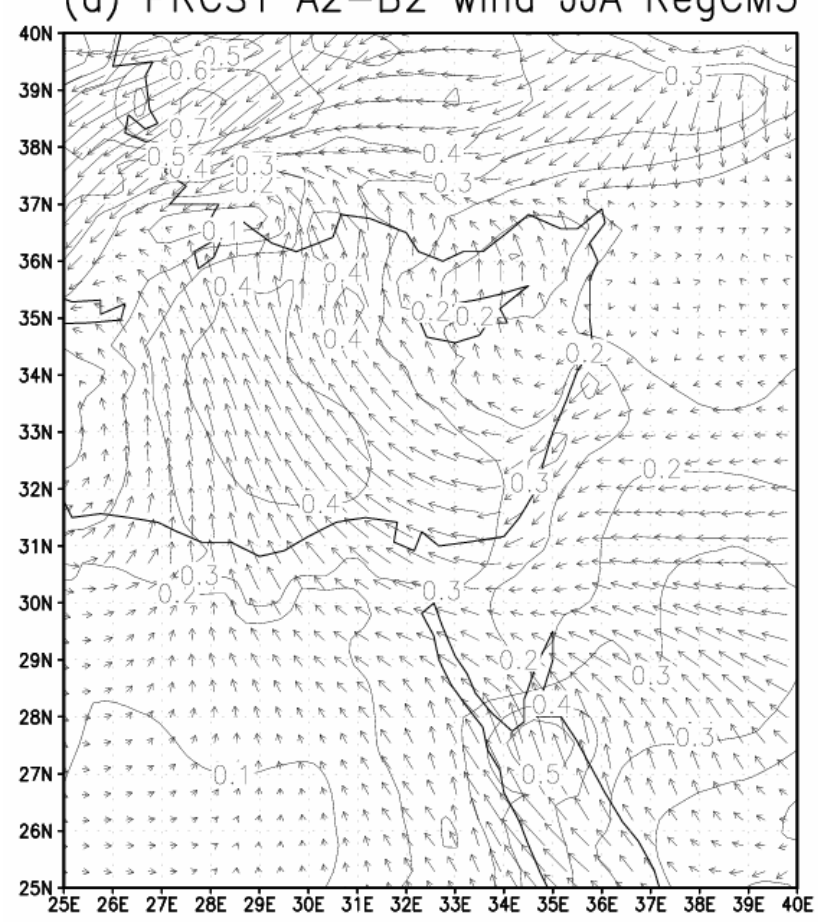

$\overrightarrow{0.8}$

Fig. 7. RCM projection of future changes in wind direction and magnitude: (a, c) A2 minus CT in DJF and JJA; (b, d) sensitivity to emission scenario (A2 minus B2) in DJF and JJA. 
(a) PRCS1 A2-CT SW net DJF RegCM3

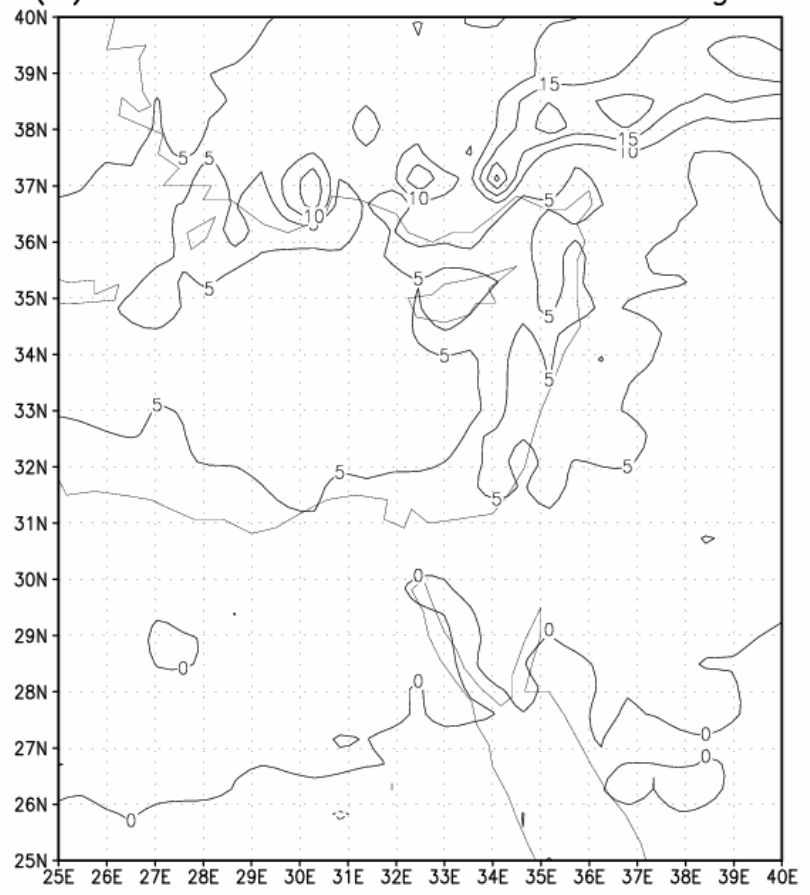

(c) PRCS1 A2-CT SW net JJA RegCM3

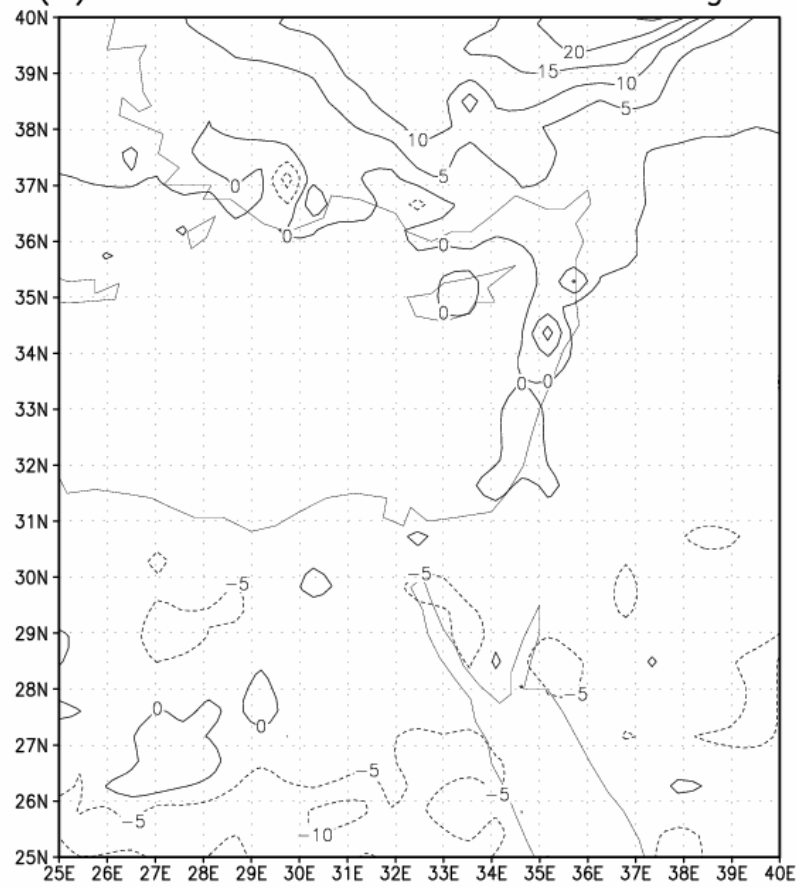

(b) PRCS1 A2-B2 SW net DJF RegCM3

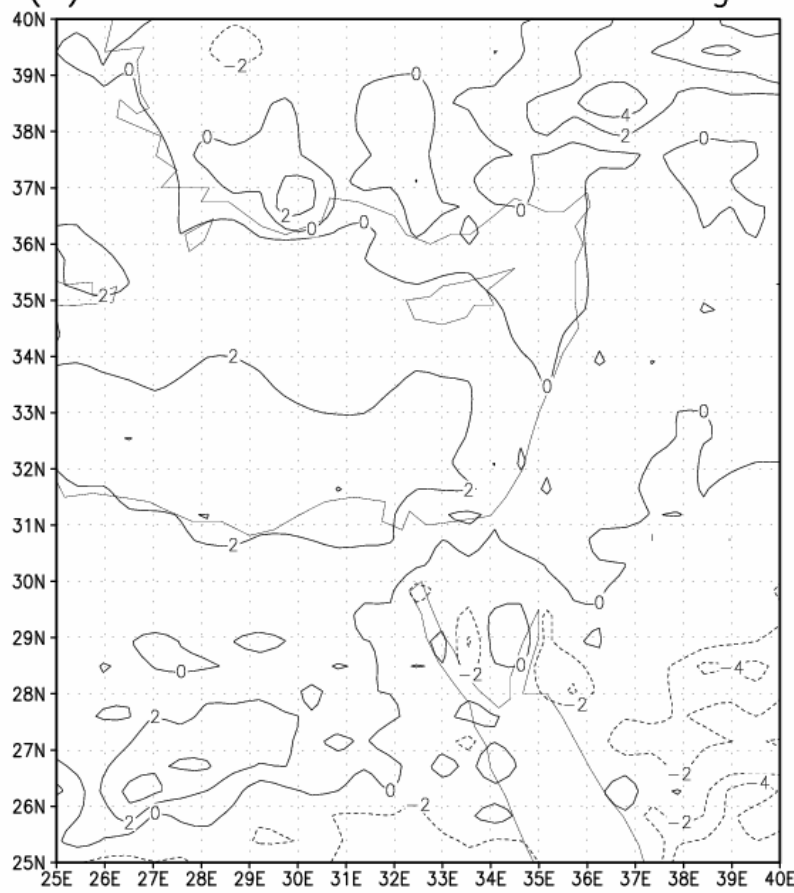

(d) PRCS1 A2-B2 SW net JJA RegCM3

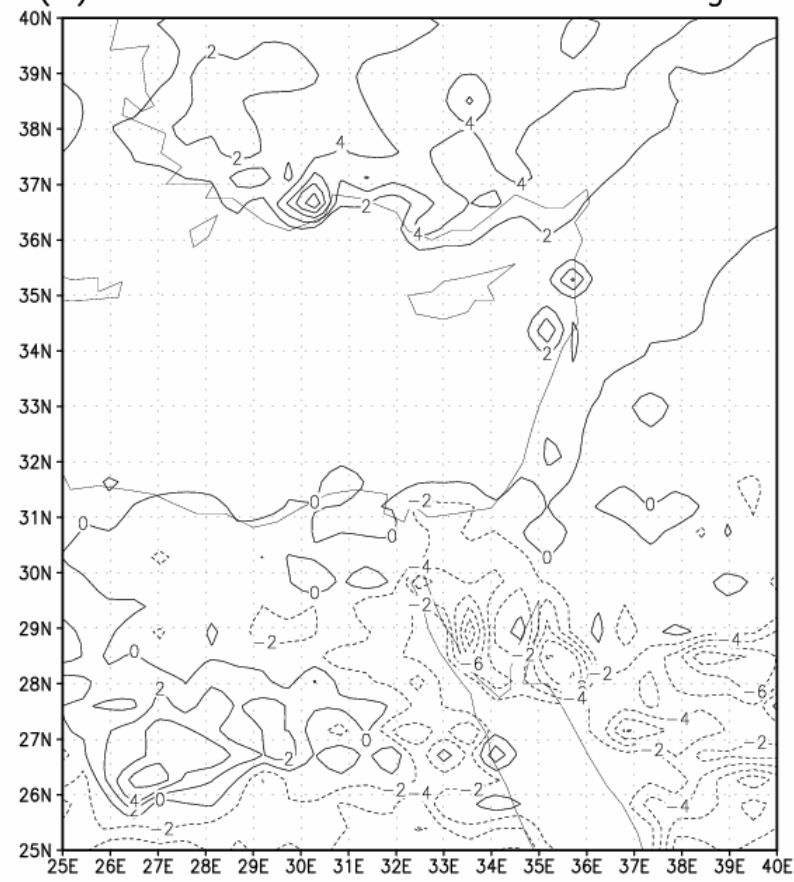

Fig. 8. Same as in Fig. 7 but for net absorbed short-wave radiation. 
(a) A2-CT SLP DJF $\mathrm{HCH}$

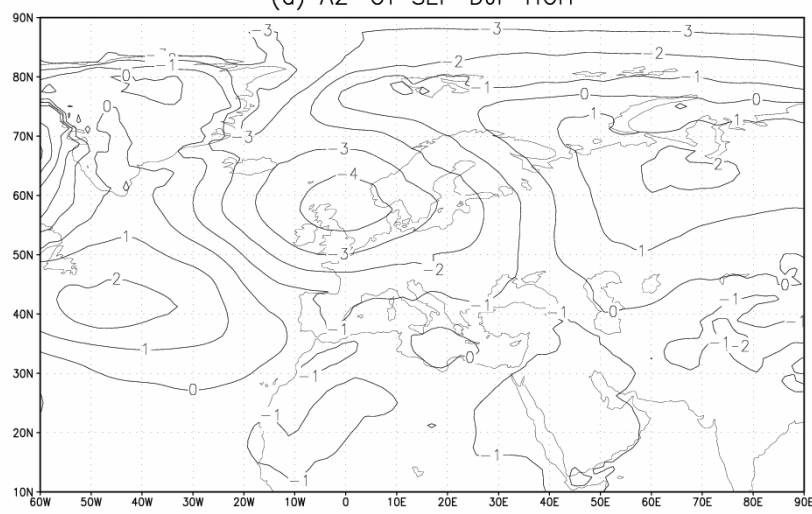

(c) A2-CT SLP JUA HCH

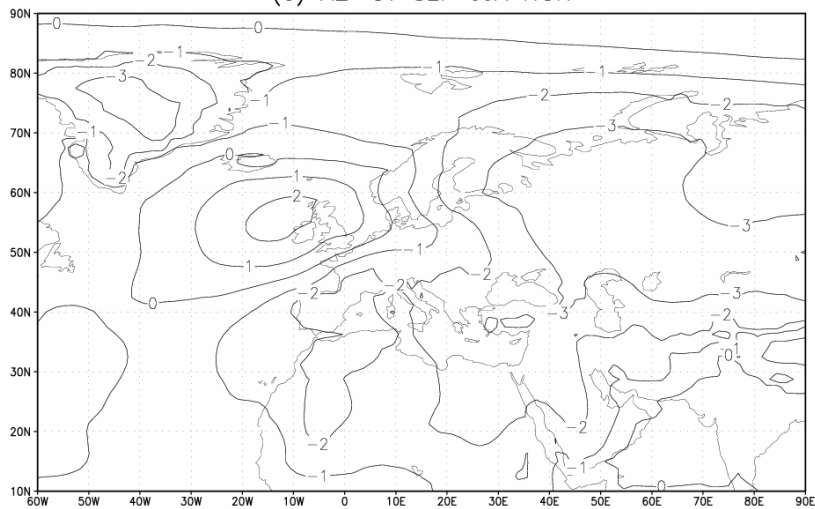

(b) A2-B2 SLP DJF $\mathrm{HCH}$

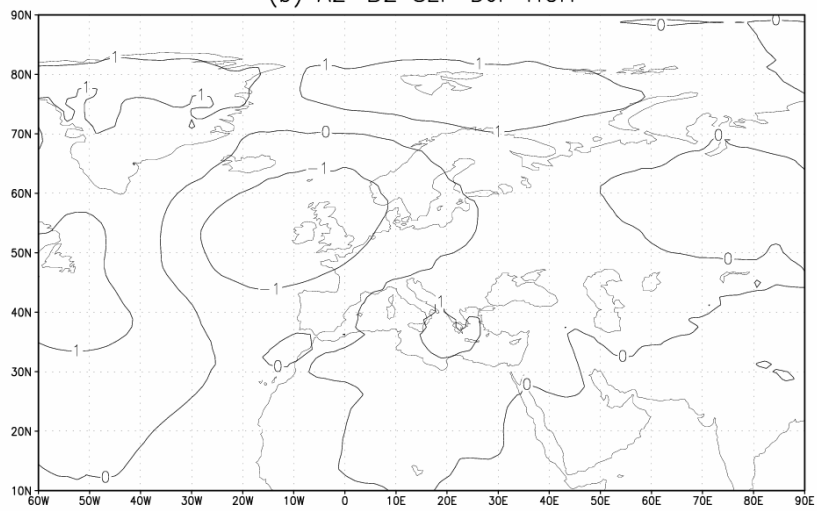

(d) A2-B2 SLP JJA HCH

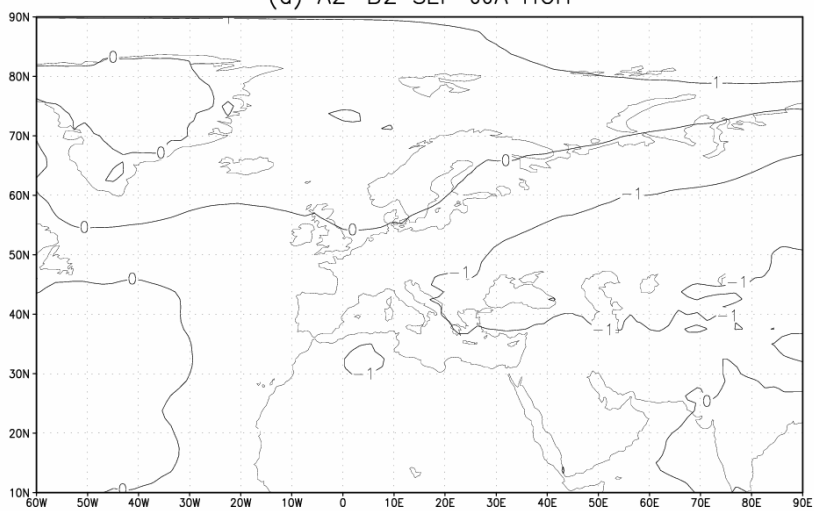

Fig. 9. Same as in Fig. 7 but for sea level pressure and based of results of HadAM3H global simulation experiment.

According to Fig. 9b the B2 scenario GHG emission will lead to formation of a similar (though weaker) SLP anomaly pattern - which is also in agreement with the pattern in Fig. $7 b$.

According to Fig. 9c, the a large-scale climate change process over Europe during JJA will be associated with development of a negative SLP anomaly over central and east Russia and positive SLP anomaly over east Atlantic. Such atmospheric circulation anomaly is appropriate for predominantly northerly winds over the EM region during the season. The RegCM3-produced JJA wind change pattern (Fig. 7c) differs from that in Figs. 9c, $d$ however. The fact seems to be indicating a regional origin of the RCM-produced JJA wind field A2-CT wind circulation changes in JJA season.

\section{Discussion}

Three current climate and climate change simulation experiments have been performed. Analysis of 30-year mean seasonal patterns of several produced in the experiments parameters allows evaluation of uncertainty in the results obtained. The fact that all the RCM experiments performed did not reproduce the sharp east-west gradient of the precipitation distribution may be attributed to an insufficient size of the model domain chosen as well as the space resolution adopted. The current climate PRCS1/PRCS2-based temperature and air-moisture patterns are in better agreement with the observations than those of the FVGCM experiment. Though the PRCS1/PRCS2 experiments reasonably accurately reproduced the real annual precipitation pattern, the corresponding FVGCM-based pattern is in a better agreement with the observations. At the same time the FVGCM-based climate is characterized by a positive air moisture bias. The facts seem to be indicating an insufficiency in the moist air mass influx from the lateral boundaries in the PRCS1/PRCS2 runs. Both possible inadequacies in the AOGCM formulations and insufficient RCM domain size (Vannitsem and Chome, 2005) may be contributing to those in the boundary forcing. A higher accuracy of the annual precipitation pattern produced by Giorgi at al. (2004a) over a larger model domain supports the latter suggestion.

Based on the results of the study as well as those of the earlier analyses of the EM precipitation-wind field relationships (Krichak and Alpert, 2005) a significant increase of 
the model domain size to include into consideration synoptic processes over southern Europe and E. Atlantic is planned. The current results allow however a preliminary conclusion about the EM climate change expected. Namely, weakening of DJF and JJA westerly air flows over the central part of the EM, intensification of the northerly flows over Cyprus Island and increase of intensity of the SW radiative fluxes over the northern (DJF and JJA) and central (DJF) part of the region are projected for the end of the 21 st century. The changes projected are in agreement with the earlier climate change estimates (Giorgi et al., 2004b) in respect to temperature (increase) and annual precipitation (decrease). Results of the experiment allow an understanding of the EM climate change processes expected. The climate change processes during the cool season (DJF) appear to be mainly associated with the large-scale developments over Europe. Different mechanisms, mainly associated with smaller-scale regional EM and summer Asian monsoon, control projected climate change processes during JJA.

Acknowledgements. The research was supported by German-Israeli research grant (GLOWA - Jordan River) from the Israeli Ministry of Science and Technology; and the German Bundesministerium fuer Bildung und Forschung (BMBF). The HadAM3P (PRECIS) driving data have been provided by the Met Office Hadley Centre, University of Reading, UK. The NASA FV-GCM driving data as well as results of the RegCM2 simulations performed for the EU PRUDENCE Project have been provided by the International Centre for Theoretical Physics (ICTP), Trieste. Grid-point data from the Climate Research Unit (CRU) of the University of East Anglia, UK have been used for verification of the results of the climate simulations performed. M. Dayan participated in realization of the PRCS1 experiment. We thank X. Bi for help in our work with the RegCM3. We also much appreciated the constructive comments of the anonymous reviewers.

Edited by: P. Alpert, H. Saaroni, and E. Heifetz

Reviewed by: two anonymous referees

\section{References}

Alpert, P., Price, C., Krichak, S. O., Ziv, B., Saaroni, H., Osetinsky, I., Barkan, J., and Kishcha, P.: Tropical tele-connections to the Mediterranean climate and weather, Adv. Geosci., 2, 157-160, 2005 , http://www.adv-geosci.net/2/157/2005/.

Atlas, R., Reale, O, Shen, B. W., Lin, S. J., Chern, J. D., Putman, W. T., Lee, T., Yeh, K. S., Bosilovich, M., and Radakovich, J.: Hurricane forecasting with the high-resolution NASA finite volume general circulation model, Geophys. Res. Lett., 32(3), L03807, doi:10.10292004GL021513, 2005.

Bedi, H. S., Datta, R. K., and Krichak, S. O.: Numerical forecast of summer monsoon flow pattern, Sov. Meteorol. Hydrol., USA, 5, 39-45, 1976.

Christensen, J. H., Machenhauer, B., Jones, R. G., Schaar, C., Ruti, P. M., Castro, M, and Visconti, G.: Validation of presentday regional climate simulations over Europe: LAM simulations with observed boundary conditions, Clim. Dynam., 13, 489-506, 1997.

Christensen, J. H. and Christensen, O. B.: Severe summertime flooding in Europe, Nature, 421, 805-806, 2003.

Deque, M., Jones, R. G., Wild, M., Giorgi, F., Christensen, J. H., Hassell, D. C., Vidale, P. L., Rockel, B., Jacob, D., Kiellstrom, E., de Castro, M., Kucharski, F., and van den Hurk, B.: Global high resolution versus limited area model climate change projections over Europe: quantifying confidence level from PRUDENCE results, Clim. Dyn., 25, 653-670, 2005.

Evans, J. P., Smith, R., and Oglesby, R.: Middle East climate simulation and dominant precipitation processes, Int. J. Climatol., 24, 1671-1694, 2004.

Giorgi, F., Bi, X., and Pal, J.: Mean, interannual variability and trends in a regional climate change experiment over Europe. I. Present-day climate (1961-1990), Clim. Dynam., 22, 733-756, 2004a.

Giorgi, F., Bi, X., and Pal, J.: Mean, interannual variability and trends in a regional climate change experiment over Europe. II. climate change scenarios (2071-2100), Clim. Dynam., 23, 839858, 2004b.

IPCC: Emission scenarios, a special report of working group III of the intergovernmental panel on climate change, Nakicenovic N, Coordinating Lead Author, Cambridge UniversityPress, Cambridge, p. 599, 2000.

Johns, T. C., Gregory, J. M., Ingram, W. J., Johnson, C. E., Jones, A., Lowe, J. A., Mitchell, J. F., Roberts, D. L., Sexton, D. M. H., Stevenson, D. S., Tett, S. F. B., and Woodage, M.: Anthropogenic climate change for 1860 to 2100 simulated with the HadCM3 model under updated emissions scenarios, Clim. Dynam., 20, 583-612, 2003.

Krichak, S. O. and Alpert, P.: Eastern Mediterranean precipitation climate modeling and analysis evaluations, Geophys. Res. Abstr., 6, 05781, 2004.

Krichak, S. O. and Alpert, P.: Decadal trends in the East Atlantic/West Russia pattern and the Mediterranean precipitation, Int. J. Clim., 25, 183-192, 2005.

Krichak, S. O., Alpert, P., and Dayan, M.: Adaptation of the MM5 and RegCM3 for regional, climate modeling over the eastern Mediterranean, region, Geophys. Res. Abstr., 7, 04624, 2005.

Krichak, S. O., Alpert, P., and Dayan, M.: An evaluation of role of hurricane Olga (2001) in an extreme rainy event in Israel using dynamic tropopause maps, Meteorol. Atmos. Phys., doi:10.1007/s00703-006-0230-7, in press, 2007.

Leckebusch, G. C., Koffi, B., Ulbrich, U., Pinto, J. P., Spangehl, T., and Zacharias, S. :Analysis of frequency and intensity of European winter storm events from a multi-model perspective at synoptic and regional scales, Clim. Res., 31, 59-74, 2006.

Mitchell, T. D., Carter, T. R., Jones, P. D., Hulme, M., and New, M.: A comprehensive set of high-resolution grids of monthly climate for Europe and the globe: the observed record (1901-2000) and 16 scenarios (2001-2100), Tyndall Centre Working Paper No. 55., Tyndall Centre for Climate Change Research, University of East Anglia, Norwich, UK, 2004.

Pal, J. S., Giorgi, F., Bi, X., Elguindi, N., Solmon, F., Gao, X., Francisco, R., Zakey, A., Winter, J., Ashfaq, M., Syed, F. S., Bell, J. L., Diffenbaugh, N. S., Karmacharya, J., Konare, A., Martinez, D., da Rocha, R. P., Sloan, L. C., and Steiner, A. : The ICTP RegCM3 and RegCNET: regional climate modeling for the de- 
veloping world, B. Am. Meteorol. Soc., in press, 2007.

Raupach, M. R., Marland, G., Ciais, Ph., Le Quéré, C. Canadell, J. G., Klepper, G., and Field, C. B.: Global and regional drivers of accelerating $\mathrm{CO}_{2}$ emissions, Proc. Nat. Acad. Sci. USA, available online: www.pnas.org/cgi/doi.10.1073/pnas.0700609104, 2007.
Vannitsem, S. and Chome, F.: One-Way Nested Regional Climate Simulations and Domain Size, J. Climate, 18, 229-233, 2005. 